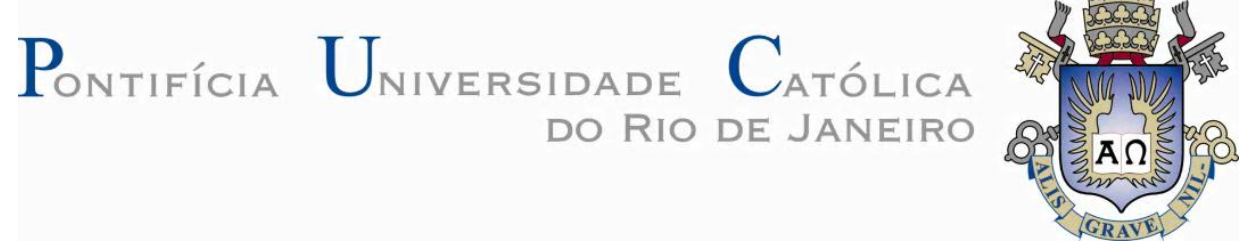

Eduardo Silva Maia

\title{
Pelotização e Redução de Concentrado Magnetítico
}

\section{Dissertação de Mestrado}

Dissertação apresentada como requisito parcial para obtenção do título de Mestre pelo Programa de PósGraduação em Engenharia de Materiais e de Processos Químicos e Metalúrgicos da PUC-Rio.

Orientadores: Prof. José Carlos D'Abreu Prof. Francisco José Moura 


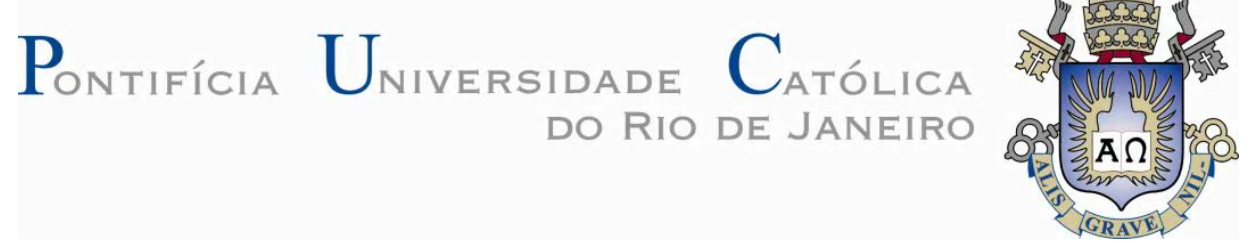

Eduardo Silva Maia

\section{Pelotização e Redução de Concentrado Magnetítico}

Dissertação apresentada como requisito parcial para obtenção do título de Mestre pelo Programa de Pós-Graduação em Engenharia de Materiais e de Processos Químicos e Metalúrgicos da PUC-Rio. Aprovada pela Comissão Examinadora abaixo assinada.

Prof. José Carlos D'Abreu

Orientador

Departamento de Engenharia de Materiais - PUC-Rio

Prof. Francisco José Moura Departamento de Engenharia de Materiais - PUC-Rio

Prof. Hélio Marques Kohler TECNOS - Inovações Tecnológicas Ltda.

Prof. José Eugênio Leal

Coordenador Setorial do Centro Técnico Científico - PUC-Rio 
Todos os direitos reservados. É proibida a reprodução total ou parcial do trabalho sem autorização da universidade, do autor e do orientador.

\section{Eduardo Silva Maia}

Graduado em Engenharia de Produção-Metalúrgica em 2005, pela Pontifícia Universidade Católica do Rio de Janeiro. Desde então, trabalha como consultor da Metal Data S/A, analisando e desenvolvendo projetos, principalmente, nas áreas de siderurgia e mineração.

Ficha Catalográfica

Maia, Eduardo Silva

Pelotização e redução de concentrado magnetítico / Eduardo Silva Maia; orientadores: José Carlos D'Abreu; Francisco José Moura. - 2011.

144 f. : il. (color.) ; $30 \mathrm{~cm}$

Dissertação (mestrado) - Pontifícia Universidade Católica do Rio de Janeiro, Departamento de Engenharia de Materiais, 2011.

Inclui bibliografia

1. Engenharia de materiais - Teses. 2. Minério de ferro. 3. Magnetita. 4. Pelotização. 5. Siderurgia. 6. Redução. 7. Tratamento de minério. I. D'Abreu, José Carlos. II. Moura, Francisco José. III. Pontifícia Universidade Católica do Rio de Janeiro. Departamento de Engenharia de Materiais. IV. Título.

CDD: 620.11 
Aos meus queridos pais e familiares, pela motivação, confiança e apoio que sempre passaram em todos os meus projetos. 


\section{Agradecimentos}

Aos meus orientadores, Prof. José Carlos D'Abreu e Prof. Francisco José Moura, pela amizade, incentivos e ensinamentos passados durante a realização deste trabalho.

À empresa Metal Data S/A, representada pelo presidente Aroldo Ceotto, e todos meus colegas de trabalho, pelo total apoio e auxílio concedido, sem os quais este trabalho não seria realizado.

À PUC-Rio, pelos auxílios concedidos para realização deste trabalho.

Ao Mauro Yamamoto e João Antônio Vilar da Silva, do laboratório Nomos Análises Minerais Ltda. e seus colaboradores, pelo apoio na realização da etapa de tratamento do minério magnetítico.

Ao Eng. Floriano Wendling, da empresa Radieng Consultoria Ltda. e seus colaboradores, pelo apoio na realização dos testes de pelotização e ensinamento ao longo deste trabalho.

Ao Eng. Raimundo Nonato Rodrigues Filho, pelo auxílio na realização dos testes de redução.

A todos os professores, colegas e a equipe do Departamento de Engenharia dos Materiais (DEMa), pela amizade e colaboração transmitida durante a execução deste trabalho.

Aos meus familiares e amigos, pelo apoio.

E principalmente, à Deus, pela minha vida. 


\section{Resumo}

Maia, Eduardo Silva; D’Abreu, José Carlos; Moura, Francisco José. Pelotização e Redução de Concentrado Magnetítico. Rio de Janeiro, 2011. 144p. Dissertação de Mestrado - Departamento de Engenharia de Materiais, Pontifícia Universidade Católica do Rio de Janeiro.

A tendência mundial de aumento da quantidade de finos (sinter feed e pellet feed) nas lavras de minério de ferro tem elevado a importância dos processos de aglomeração, em especial a pelotização, que tem por característica produzir pelotas de excelente qualidade química e alta resistência mecânica, além de ser um processo menos poluente que a sinterização. Atualmente, as jazidas de minério de ferro em lavra no Brasil, exploram minérios predominantemente hematíticos (hematita e/ou itabirito). Apesar do país não possuir tradição na exploração de minérios magnetíticos, existem ocorrências destes que vêm despertando crescente interesse, sendo, contudo, necessário à adequação das etapas do beneficiamento mineral e dos parâmetros operacionais da pelotização. O presente trabalho, fruto de uma interação da empresa Metal Data S/A e o Grupo de Siderurgia do DEMa/PUCRio, trata do estudo da pelotização de um minério de ferro magnetítico, proveniente de uma jazida brasileira em fase de pesquisa mineral, com o objetivo de analisar sua viabilidade exploratória para produção de pelotas a serem utilizadas como matéria prima na indústria siderúrgica. Os procedimentos experimentais foram divididos em três etapas: tratamento do minério, pelotização e redução, buscando assim, definir uma rota de tratamento do minério e, posteriormente, a caracterização química, mecânica e metalúrgica das pelotas produzidas. Foram estudados três tipos de misturas para a pelotização, envolvendo oito diferentes concentrados. Os resultados indicaram que o minério magnetítico é passível de concentração e capaz de produzir um pellet feed de qualidade, utilizando rota de beneficiamento com operações unitárias típicas. Este material mostrou potencial para a formação de pelotas cruas em discos de laboratório e, após as operações de queima, produziu pelotas que apresentaram granulometria entre 9,5 e 16,0 mm, resistência à compressão de 126 a $339 \mathrm{~kg} /$ pelota, índice de tamboramento de 67,7 a 94,9 \%, porosidades de 23,8 a $40,74 \%$, grau de metalização de 30 a $75 \%$, entre outras.

\section{Palavras-chave}

Minério de Ferro; Pellet Feed; Pelotas; Pelotização; Siderurgia; Redução; Tratamento de minério. 


\section{Abstract}

Maia, Eduardo Silva; D’Abreu, José Carlos (Advisor); Moura, Francisco José (Advisor). Pelletizing and Reducing of Magnetite Concentrate. Rio de Janeiro, 2011. 144p. MSc. Dissertation - Departamento de Engenharia de Materiais, Pontifícia Universidade Católica do Rio de Janeiro.

The global increasing trend of producing iron ore fines (sinter feed and pellet feed) has also increased the importance of the agglomeration processes, in particular the pelletizing, which has as main characteristic to produce high quality pellets with excellent mechanical resistance, besides being a less polluting process than the sintering. Currently, Brazilian mines exploit mainly hematite deposits (hematite and / or itabirite ores). Although the country has no tradition in exploiting magnetite minerals, there is a growing interest trend in magnetite occurrences, although it might be necessary to adequate mineral processing and pelletizing operating parameters when using such ore. This work is a result of an interaction between the company Metal Data S/A and the Siderurgy Group of the DEMa/PUC-Rio and describes the pelletizing process using magnetite iron ore from a Brazilian deposit in exploration stage, in order to evaluate its suitability for exploratory pellet production to be used as feedstock in the steel industry. The experimental procedures were divided into three steps - ore processing, pelletizing and reduction, aiming to define the ore treatment route and chemical, mechanical and metallurgical characteristics of the produced pellets. Three types of mixtures for pelletizing were analysed, involving eight different concentrates. The results indicated that the magnetite ore is likely to concentrate and capable of producing a pellet feed with adequate quality, using a processing route with typical unit operations. It was observed that this materal has a potential for the formation of green pellets in the laboratory pelletizing disc and, after burning operations, produced pellets that had particle size between 9.5 and $16.0 \mathrm{~mm}$, compression strength from 126 to $339 \mathrm{~kg} /$ pellet, tumble index from 67.7 to $94.9 \%$, porosity from 23.8 to $40.74 \%$, degree of metallization from 30 to $75 \%$, among others.

\section{Keywords}

Iron Ore; Pellet Feed; Pellets; Pelletizing; Siderurgy; Reduction; Mineral Processing. 


\section{Sumário}

1 INTRODUÇÃO 16

2 OBJETIVO 18

3 REVISÃO BIBLIOGRÁFICA 19

3.1. MINÉRIO DE FERRO 19

3.1.1. Cenário Internacional 21

3.1.2. Cenário Nacional 25

3.2. BENEFICIAMENTO MINERAL 33

3.2.1. Amostragem $\quad 34$

3.2.2. Cominuição 39

3.2.3. Índice de Trabalho 44

3.2.4. Classificação e Peneiramento 46

3.2.5. Concentração Gravítica 52

3.2.6. Separação Magnética 57

3.2.7. Flotação $\quad 62$

3.3. PELOTIZAÇÃO $\quad 64$

3.4. REDUÇÃO 67

3.4.1. Termodinâmica da Redução $\quad 67$

$\begin{array}{ll}\text { 3.4.2. Cinética da Redução } & 73\end{array}$

4 PROCEDIMENTOS EXPERIMENTAIS $\quad 75$

4.1. MATERIAIS UTILIZADOS

4.1.1. Concentrado Magnetítico 75

$\begin{array}{ll}\text { 4.1.2. Outros } & 79\end{array}$

4.2. DESENVOLVIMENTO EXPERIMENTAL 81

4.2.1. Tratamento do Minério Magnetítico 81

4.2.2. Pelotização $\quad 87$

4.2.3. Redução 98

5 RESULTADOS E DISCUSSÃO 101

5.1. TRATAMENTO DO MINÉRIO MAGNETÍTICO 101

5.1.1. Análise Química 101

5.1.2. Distribuição \%Fe por Faixa Granulométrica 101 
5.1.3. Grau de Liberação 103

5.1.4. Índice de Trabalho (WI) 104

5.1.5. Ensaio de Moagem 105

5.1.6. Ensaio de Concentração Física 110

5.2. PELOTIZAÇÃO 118

5.2.1. Ensaios Físicos 119

5.3. REDUÇÃO 127

5.3.1. Grau de Redução 127

5.3.2. Grau de Metalização 129

5.3.3. Análise Metalográfica 130

5.4. QUALIDADE DAS PELOTAS 135

6 CONCLUSÕES E RECOMENDAÇÕES 137

7 REFERÊNCIAS 140 


\section{Lista de figuras}

Figura 1 - Mineração de ferro e siderurgia ${ }^{(6)}$

Figura 2 - Evolução da produção mundial de minério de ferro (concentrado) ${ }^{(4)} 22$

Figura 3 - Capacidade de produção de minério de ferro por empresa $(2010)^{(9)} 23$

Figura 4 - Ocorrências de minério de ferro no Brasil( ${ }^{(5)} \quad 28$

Figura 5 - Evolução da produção de minério de ferro no Brasil ${ }^{(4,5)} \quad 29$

Figura 6 - Evolução do consumo aparente de minério de ferro no Brasil ${ }^{(4,11)} \quad 29$

Figura 7 - Evolução da produção pelotas no Brasil ${ }^{(1,4,5)} \quad 31$

Figura 8 - Produção e exportação de pelotas no Brasil( ${ }^{(1,4,5,11)}$

Figura 9 - Evolução do consumo aparente de pelotas no Brasil ${ }^{(1,5)}$

Figura 10 - Representação esquemática da construção de

pilhas cônica e longitudinal ${ }^{(13)}$

Figura 11 - Quarteamento da amostra em (a) pazada fracionada

e em (b) pazada alternada ${ }^{(13)}$

Figura 12 - Representação esquemática do quarteamento em pilha cônica ${ }^{(13)} 36$

Figura 13 - Representação esquemática do quarteamento e

etapas de preparação da pilha de homogeneização longitudinal ${ }^{(13)}$

Figura 14 - Quarteador Jones ${ }^{(12)} \quad 38$

Figura 15 - Mesa homogeneizadora ${ }^{(13)} \quad 38$

Figura 16 - Mesa divisora ${ }^{(13)} \quad 39$

Figura 17 - Britador de mandíbulas de dois eixos ${ }^{(15)} \quad 40$

Figura 18 - Britador de impacto ${ }^{(15)} \quad 41$

Figura 19 - Britador de rolo dentado ${ }^{(12)} \quad 41$

Figura 20 - Britador cônico $\quad 42$

Figura 21 - Britador de rolos $\quad 42$

Figura 22 - Moinho para testes de índice de trabalho de Bond para moagem 45

$\begin{array}{ll}\text { Figura } 23 \text { - Partes de um hidrociclone }{ }^{(12)} & 47\end{array}$

Figura 24 - Três formas de descarga do underflow do hidrociclone ${ }^{(13)} \quad 48$

Figura 25 - Esquema de uma espiral (Humphreys) 55

Figura 26 - Separador magnético de imãs de terras-raras 58

Figura 27 - Separador magnético de correias cruzadas de três estágios ${ }^{(13)} \quad 59$

Figura 28 - Separador de rolos induzidos com três estágios de separação ${ }^{(13)} 60$

Figura 29 - Separador magnético de tambor 61

Figura 30 - Separador magnético a úmido de alta intensidade (WHIMS)

da Gaustec 
Figura 31 - Diagrama Fe-O $\quad 67$

Figura 32 - Diagrama de equilíbrio Fe-C ${ }^{(28)} \quad 69$

Figura 33 - Diagrama de Chaudron (oxi-redução) ${ }^{(28)} \quad 71$

Figura 34 - Efeito da variação de pressão sobre o equilíbrio

da reação de Boudouard ${ }^{(28)} \quad 72$

Figura 35 - Representação esquemática do modelo topoquímico 73

Figura 36 - Aspecto típico da formação ferrífera 75

Figura 37 - Mapa geológico e posicionamento das amostras coletadas $\quad 76$

Figura 38 - Fluxograma de tratamento do minério magnetítico 78

Figura 39 - Preparação do minério ROM (Amostra G)

para ensaios de caracterização tecnológica 82

Figura 40 - Análise granulométrica para determinação do grau de liberação 83

Figura 41 - Tambor para homogeneização da mistura 89

Figura 42 - Disco de pelotização $\quad 91$

Figura 43 - Forno de grelha reta $\quad 91$

Figura 44 - Forno rotativo $\quad 92$

Figura 45 - Perfil térmico de queima das pelotas RD 92

Figura 46 - Perfil térmico de queima das pelotas AF I 93

Figura 47 - Perfil térmico de queima das pelotas AF II 93

Figura 48 - Equipamento para determinação da resistência à

compressão das pelotas cruas 95

Figura 49 - Equipamento para determinação da resistência à compressão das pelotas queimadas 96

Figura 50 - Equipamento para ensaio de abrasão e tamboramento 98

Figura 51 - Forno (COMBUSTOL) utilizado para o ensaio de redução 99

Figura 52 - Curva de distribuição granulométrica corrigida 102

Figura 53 - Curva de grau de liberação 103

Figura 54 - Distribuição granulométrica do material de alimentação

$\begin{array}{ll}\text { do ensaio de moagem } & 106\end{array}$

Figura 55 - Distribuição granulométrica para o produto

$\begin{array}{ll}\text { da moagem a } 1 \text { minuto } & 106\end{array}$

Figura 56 - Distribuição granulométrica para o produto

da moagem a 2 minutos

Figura 57 - Distribuição granulométrica para o produto

da moagem a 4 minutos 
Figura 58 - Distribuição granulométrica para o produto da moagem a 8 minutos

Figura 59 - Distribuição granulométrica para o produto da moagem a 16 minutos

Figura 60 - Distribuição granulométrica para o produto da moagem a 32 minutos

Figura 61 - Curva tempo de moagem vs P80

Figura 62 - Fotografia das pelotas quebradas no teste de resistência à compressão

Figura 63 - Pelota AF I; posição: núcleo; aumento: 100x

Figura 64 - Pelota AF I; posição: meio raio; aumento: 100x

Figura 65 - Pelota AF I; posição: superfície; aumento: 100x

Figura 66 - Pelota RD; posição: núcleo; aumento: 100x 133

Figura 67 - Pelota RD; posição: meio raio; aumento: 100x 134

Figura 68 - Pelota RD; posição: superfície; aumento: 100x 


\section{Lista de tabelas}

Tabela 1 - Características da hematita vs magnetita 20

Tabela 2 - Produção e reservas de minério de ferro por país ${ }^{(3,4)} \quad 21$

Tabela 3 - Ranking das 10 maiores empresas produtoras mundiais de minério de ferro $(2010)^{(4)} 22$

Tabela 4 - Evolução da importação e exportação

de minério de ferro por país ${ }^{(8)} \quad 24$

Tabela 5 - Recursos \& reservas de minério de ferro brasileiro ${ }^{(5)} \quad 26$

Tabela 6 - Capacidade atual de produção de pelotas ${ }^{(5)} \quad 30$

Tabela 7 - Capacidade adicional de produção de pelotas (até 2015) ${ }^{(5)} \quad 31$

Tabela 8 - Distribuição dos diâmetros das bolas da carga moedora ${ }^{(17)} \quad 45$

Tabela 9 - Correlação das escalas Tyler, Richards e a abertura da peneira ${ }^{(21)} 50$

Tabela 10 - Critério de concentração e separação gravítica ${ }^{(22)} 52$

Tabela 11 - Produtividade e consumo específico de combustível

na pelotização por tipo de minério ${ }^{(25)} \quad 66$

Tabela 12 - Mecanismo controlador em função da redução

do óxido de ferro ${ }^{(29,32)} \quad 74$

Tabela 13 - Análise química do minério $\operatorname{ROM}$ (Amostra G) 76

Tabela 14 - Amostras de ROM

Tabela 15 - Massa e análise química (\%) dos concentrados magnetíticos 79

Tabela 16 - Análise química do calcário calcítico 80

Tabela 17 - Análise química do carvão antracito $\quad 80$

Tabela 18 - Análise química da bentonita 80

Tabela 19 - Distribuição das bolas de moagem 86

Tabela 20 - Tempo de moagem vs P80 86

Tabela 21 - Análise química (\%) dos pellet feed para pelotização 88

Tabela 22 - Análise comparativa dos pellet feed produzidos

com os de duas grandes mineradoras nacionais e uma estrangeira 88

Tabela 23 - Massa em kg dos insumos de cada mistura 89

Tabela 24 - Especificações químicas calculadas para as misturas 90

Tabela 25 - Análises químicas da basicidade binária das misturas 90

Tabela 26 - Análise granulométrica das misturas 90

Tabela 27 - Análise química do minério $\operatorname{ROM}$ (Amostra G) 101

Tabela 28 - Distribuição granulométrica corrigida 102 
Tabela 29 - Distribuição \%Fe por faixa granulométrica

Tabela 30 - Dados para determinação do índice de trabalho

$\begin{array}{ll}\text { para moagem de Bond } & 104\end{array}$

Tabela 31 - Dados para determinação do índice de britagem de Bond 105

Tabela 32 - Distribuição granulométrica P80 = 35\# 110

Tabela 33 - Distribuição granulométrica P80 = 42\# 111

Tabela 34 - Distribuição granulométrica P80 = 60\# 111

Tabela 35 - Distribuição granulométrica P80 = 100\# 112

Tabela 36 - Distribuição granulométrica P80 = 150\# 112

Tabela 37 - Resultado separação meio denso (Amostra G, P80 = 35\#) 113

Tabela 38 - Resultado separação meio denso (Amostra G, P80 = 42\#) 113

Tabela 39 - Resultado separação meio denso (Amostra G, P80 = 60\#) 114

Tabela 40 - Comparação de produtos leves e pesados até

a fração +150 \# para diferentes $P_{80}$

Tabela 41 - Resumo da mineralogia da fração de pesado do ROM

(Amostra G, P80 = 35\#)

Tabela 42 - Resumo da mineralogia da fração de leve do ROM

(Amostra G, P80 = 35\#) 116

Tabela 43 - Separação magnética "Frantz" da fração de pesado

do ROM (Amostra G, P80 = 35\#) 117

Tabela 44 - Distribuição granulométrica do sinter feed 117

Tabela 45 - Análise química das pelotas queimadas 119

$\begin{array}{ll}\text { Tabela } 46 \text { - Umidade (pelota crua) } & 119\end{array}$

Tabela 47 - Número de quedas (pelota crua) 120

Tabela 48 - Resistência à compressão (pelota crua) 120

Tabela 49 - Resistência à compressão (pelota seca) 121

Tabela 50 - Resistência à compressão - Pelotas AF I (-12,5 mm +9,5mm) 122

Tabela 51 - Resistência à compressão - Pelotas AFII (-12,5 mm +9,5 mm) 122

Tabela 52 - Resistência à compressão - Pelotas RD (-12,5 mm +9,5 mm) 122

Tabela 53 - Variação do teor de FeO na pelota com a queima 123

Tabela 54 - Porosidade das pelotas $\quad 125$

Tabela 55 - Distribuição granulométrica das pelotas 126

Tabela 56 - Índice de abrasão e tamboramento das pelotas 126

Tabela 57 - Grau de redução das pelotas AF I 128

Tabela 58 - Grau de redução das pelotas AF II 128

Tabela 59 - Grau de redução das pelotas RD 129 
Tabela 60 - Grau de redução das pelotas RD

(diferente condição operacional) 129

Tabela 61 - Grau de metalização das pelotas 129

Tabela 62 - Grau de metalização da pelota AF I (não magnética) 130

Tabela 63 - Análise comparativa das pelotas produzidos

com as de duas grandes pelotizadoras nacionais e uma estrangeira 136 